\title{
Psychological Capital Intrusion Towards Employee Performance and Counter Productive Behaviour
}

\author{
ASIA ZAMAN \\ PhD-Scholar, Institute of Business Studies and Leadership \\ Abdul Wali Khan University, Mardan \\ Asia.maju123@gmail.com \\ MINHAS ALI KHAN \\ Banking Services Officer, Allied Bank Limited \\ Minhasali24@gmail.com \\ ASAD SARFARAZ KHAN \\ PhD-Scholar, Institute of Business Studies and Leadership \\ Lecturer, Institute of Business Studies and Leadership \\ Abdul Wali Khan University, Mardan \\ Asad_as2002@hotmail.com
}

\begin{abstract}
The research study inspects the construct of three factor model i.e. Psychological Capital $(P C)$, Counter Productive Work Behaviour (CWB) and Employee Performance (EP). Questionnaire on cross-sectional basis distributed among 285 faculty members of eight public and private universities of KP, Pakistan. Confirmatory factor analyses (CFA), structure equation modelling (SEM), multiple regression and correlation statistical tools were utilized to analyze the data. All the hypotheses of the study were supported. Study depicts that PC significantly intervene towards controlling CWB that further leads towards better EP. Recommendation and future area of research were also incorporate in the study.
\end{abstract}

Keywords: Psychological Capital, Counterproductive Work Behavior, SEM

\section{Introduction}

Counter Productive Work Behaviour (CWB) refers to the behaviour of employees that harms an organization or its members (Spector \& Fox, 2002) and it includes such acts as theft, sabotage, verbal abuse, withholding of effort, lying, refusing to cooperate and physical assault (Penney \& Spector, 2005). As a result of investigation done by other Western scholars, different terminologies surfaced which implied the same meaning as CWB as: organizational delinquency (Hogan \& Hogan, 1989), organizationmotivated aggression (O' Leary-Kelly et al., 1996), organizational retaliatory behaviours, workplace aggression and workplace deviance (Robinson \& Bennet, 1995), revenge and intimidation (Gallagher et al., 2008) and antisocial behaviour in organizations (Lee et al., 2005). CWB occurrences in organizations had posed adverse effects on both organizations in terms of low productivity, increased insurance costs, lost or damage 
property and increased turnover (Leblanc and Kelloway, 2002; Penney and Spector, 2002) and the people in terms of increased dissatisfaction (Keashly et al., 1994) and expressed job stress. Such losses to organization and negative emotions to individuals will only affect organizational performance as proven by (Dunlop \& Lee, 2004; Harper, 1990). These behaviours are likely to be influenced by individuals personality traits and attitudes (Douglas \& Martinko, 2001), environmental antecedents, such as job stressors (Penney \& Spector, 2005) and organizational variables such as employment relationships, psychological contract violations and organizational justice (Penny \& Spector, 2005). In view of the costs, most research has focused on predicting CWB in an attempt to understand why individuals would engage in these behaviours and how they might be prevented. CWB is not a new phenomenon in Pakistan evidences from the Pakistan indicated that cases of theft, stealing, fighting at work and insubordination are common cases to find. Unfortunately, there is no formal statistics on the phenomenon of CWB produced by the Malaysia Labour Department (Shamsudin \& Rahman, 2006).

The construct of psychological capital (PC) was based on the emerging field of positive organizational behaviour (Luthans \& Youssef, 2007). Psychological capital deals with the study and application of psychological capacities and positively oriented human resource strengths that can be measured, enhanced, and effectively managed for the purpose of performance enrichment (Luthans, 2002). Most of the studies on CWB, Psychological Capital (PC), and Employee Performance (EP) have been undertaken by Western scholars. Very few studies in context of CWB, PC and EP were conducted by Asian researchers. Therefore, more empirical evidence on the predictors of CWB needs to be further investigated especially in the Asian countries. The purpose of this study is to explore the relationship of $\mathrm{PC}, \mathrm{EP} \& \mathrm{CWB}$ at workplace and to examine the impact of PC on CWB and EP and CWB on EP. In order to meet the objectives the study the targeted area was Public Sector Universities of Pakistan. This study was attempted to help the concerned authorities of educational institution to overcome the problem of CWB at workplace and was based on the researcher's knowledge, studies examining the relationship between psychological contract violations (Robinson \& Brown, 2004) and person-organization fit (Vardi \& Weiner, 1996). This induces the interest of the researcher to study the relationship of PC and EP with CWB in the Public Sector Universities of Pakistan as the sample demands.

\section{Literature Review}

\subsection{Psychological Capital and Employee Performance}

Among the numerous positive constructs that have been studied (Nelson \& Cooper, 2007) the four that have best met the standards of PC are hope, resilience, optimism and efficacy (Luthans, 2002; Luthans etal., 2007). The combination of these four constructs, conceptually (Luthans \& Youssef, 2004; Luthans etal., 2007) and empirically (Luthans etal., 2007) leads to the representation of a second-order core factor of PC and defined as the positive psychological state of development of an individual. This state of development is characterized by sticking with goals and redirecting goal paths when required (hope), having confidence to succeed at challenging tasks by putting in the needed effort (self-efficacy), sustaining and bouncing back after adversity and crisis (resilience), and making a positive ascription about succeeding in the present and future (optimism) (Luthans etal., 2007). Through PC, these constructs collectively form a 
unique element of the positive aspect of individuals' work life (Avey etal., 2010). These positive capacities are considered to be crucial to performance outcomes and human motivation in the organizations (Avey etal., 2010; Stajkovic, 2006).

To date, performance has been the most researched outcome variable in research on PC. This has included multiple types of performance (e.g., creative tasks, sales, referrals, quality and quantity of manufacturing, supervisor rated) and multiple sample characteristics (e.g., cross-sectional, service, manufacturing, and the highly educated). In each case, the theoretical position consistently advanced is that the mechanisms in the components of PC act as individual motivational propensities and effort to succeed resulting in increasing performance output. To understand this effect on performance in a broader context, research has pointed) a comprehensive model of performance in which there are eight dimensions of predictors (Campbell, McCloy, Oppler \& Sager, 1993). These include: (1) job-specific task proficiency (2) non-job-specific task proficiency (3) written and oral communications (4) demonstrating effort (5) maintaining personal discipline (6) facilitating peer and team performance (7) supervision/leadership and (8) management/administration. In this case, PC relates to employee performance mainly through the dimension of demonstrating effort. That is, overall, when employees try harder to succeed, they generally perform better. Individuals higher in PC are likely to be energized and put forth effort that is manifested in higher performance over extended periods of time. This is because those higher in efficacy apply effort toward goals they personally believe they are capable of achieving.

\subsection{Psychological Capital and Counter Productive Work Behaviour}

Individuals higher in $\mathrm{PC}$ would seem to be more likely to engage in Organizational Citizenship Behaviours (OCBs) than those with lower PC for several reasons. In general, employees who are more positive would seem to exhibit more OCBs than employees who tend to be negative. Several relevant mechanisms could provide support for the conceptualization of this relationship. Fredrickson's (2003) model supports a broadening contribution of positive emotions; in which people experiencing those emotions utilize broader thought-action repertoires, increasing the potential for proactive extra-role behaviours such as sharing creative ideas or making suggestions for improvement. There are also recent organizationally-based studies that have used this broadened-build model to test the role of positively-oriented psychological well-being as a moderator of both the relationship between job satisfaction-job performance (Wright, Cropanzano \& Bonett, 2007) and job satisfaction-employee turnover (Wright \& Bonett, 2007). Besides that the role of positive well-being for both in-role performance and turnover behaviors, the specific characteristics of the positive psychological resources that constitute PC, namely hope, resilience, optimism and efficacy, we propose may to lead to more frequent engagement in extra-role (i.e., broaden-and-build) OCBs.

To understand a negative relationship between PC and CWBs, an examination of the source of CWBs seems important. Specifically, Fox and Spector (1999) advance the argument that workplace constraints, acting as stressors, are the primary cause of CWBs. First, employees are exposed to stressors (e.g., having to rely on incompetent colleagues in order to personally succeed) and then respond with CWBs (e.g., failing to help a coworker or sabotage). An important mechanism in the relationship may be that individuals higher in PC are less susceptible to the negative influence of stressors, and thus exhibit 
fewer CWBs. Specifically, those high in PC may be more resilient to stressful events, stressors and setbacks (Masten \& Reed, 2002) and do not experience the negative repercussions as strongly. In addition, when exposed to stressors, instead of responding with CWBs, individuals high in PC would be expected to remain optimistic that the situation will improve (Carver \& Scheier, 2002), generate plans and pathways to change the situation for the better (Snyder et al., 2000). Based on above captioned discussion the following are the hypotheses of the study.

\subsection{Conceptual Framework}

Conceptual framework of the study is as follow namely, PEC model.

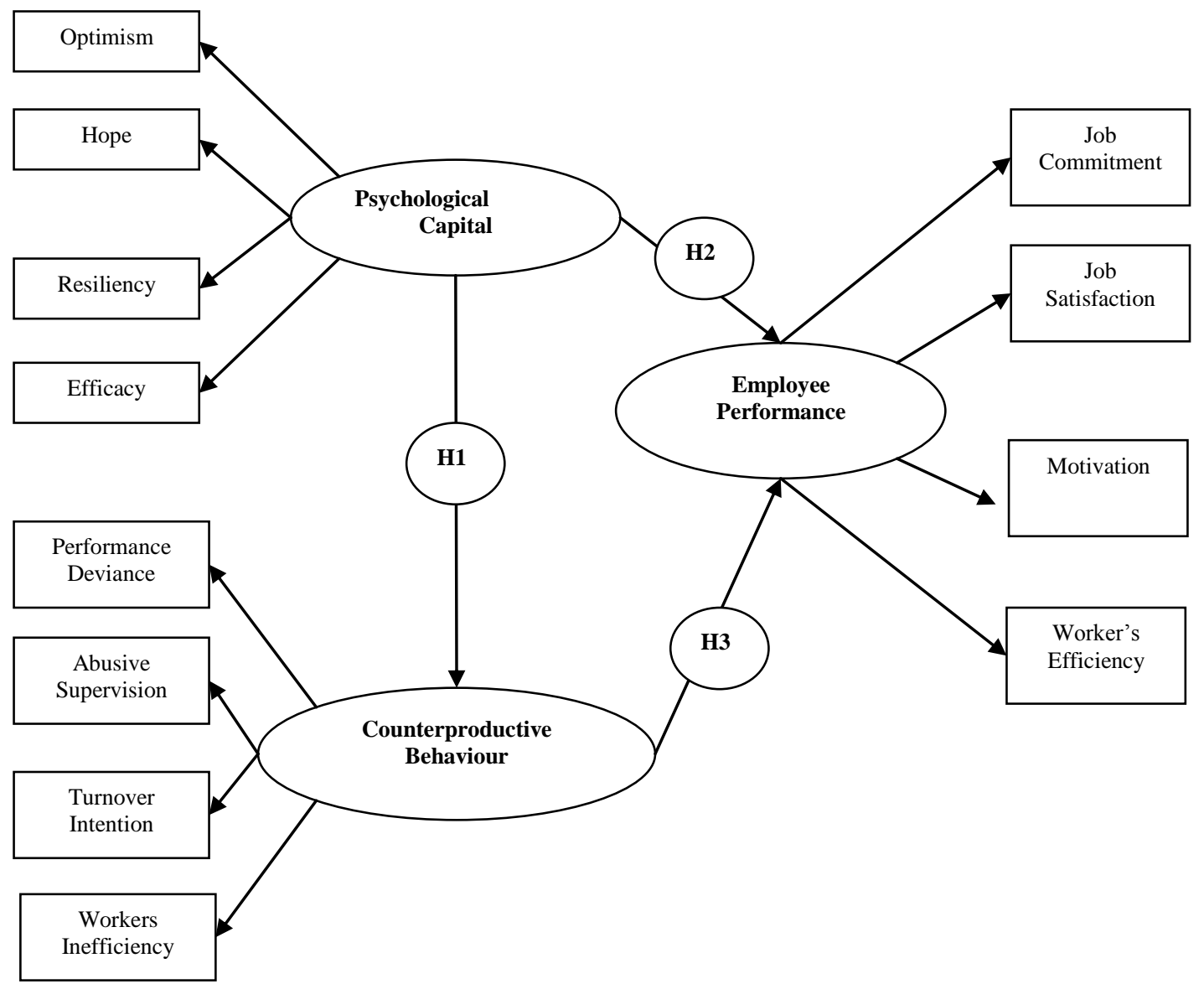

2.4 Hypotheses of the Study: Hypotheses of the study are as follows:

H1: PC has significant positive impact on controlling $C W B$

H2: PC has significant positive impact on EP.

H3: Controlled CWB has significant positive impact on EP

\section{Methodology}

\subsection{Population and Sample Size}

Staff members of eight universities of KP, Pakistan namely, University of Peshawar, Kohat University, Bannu University, Hazara University, Abdul Wali Khan University, Mardan, Bacha Khan University Charsadda, Ghulam Ishaq Khan (GIKI) 
Topi, Preston and City University Peshawar were the target population of the study. Total population in eight universities were 1000 male and female staff members. The Sample size was determined by the formula of (Guddwin, 2004). The final sample was consisted of 285 staff members. Simple random sampling technique for data collection was used in the study.

\begin{tabular}{cccc}
\hline Population $(\mathbf{N})$ & Formula & \multicolumn{1}{c}{ Computation } & Sample \\
\hline 1000 & $\mathrm{n}=\mathrm{N} / 1+\mathrm{N}^{*} \mathrm{e}^{2}$ & $\mathrm{n}=1000 / 1+1000^{*}(.05)^{2}$ & 285 \\
& $\mathrm{n}=1000 / 1+1000^{*} .0025$ & \\
& $\mathrm{n}=1000 / 3.5$ & \\
& &
\end{tabular}

\subsection{Measures}

The contents of the questionnaire was consists of two parts. Part $1^{\text {st }}$ have no score attached to it and was based on demographic information selection. Part $2^{\text {nd }}$ was built on five point Likert scale ranging from ( $1=$ strongly disagree to $5=$ strongly agree) and collect the data about PC, CWB and EP.

\subsection{Psychological Capital (PC)}

The measurement item for PC including (optimism, hope, resiliency and selfefficacy) were taken from the study of (Luthans \& Yossef, 2004; Luthans etal., 2007; Avey etal., 2010; ). After minor changes in questionnaire total 16 items were constructed on Likert scale (5-point). Reliability scale Cronbach's $\alpha$ was found .836 .

\subsection{Counter Productive Work Behavior (CWB)}

For the measurement of CWB the factors were chosen with small changes from the study of (Wright \& Bonett, 2007; Fox and Spector, 1999; Masten \& Reed, 2002). Total 16 items were built on Likert scale (5-point). Cronbach's $\alpha$ was found .812.

\subsection{Employee Performance}

The measurement item of employee performance including (job commitment, job satisfaction, employee motivation and working efficiency) was based on Likert scale (5point). The items were taken from the study of (Mahmood \& Hanafi, 2013; Manzoor \& Jalil, 2014). Cronbach's $\alpha$ was found .849.

\section{Result of the Study}

This segment of the study demonstrates the data analysis that incorporated descriptive statistics and confirmatory factor analysis (CFA's) through structure equation model (SEM).

\begin{tabular}{llcccccc}
\multicolumn{8}{c}{ Table 1: Descriptive Analysis } \\
\hline Mitle & Management Level & Male & Female & Total & Percentage & $\boldsymbol{\mu}$ & S.D \\
& Professors & 35 & 10 & 45 & $15 \%$ & & \\
& Assistant Professors & 50 & 10 & 60 & $21 \%$ & 1.42 & .498 \\
& Lecturers & 140 & 40 & 180 & $63 \%$ & & \\
Total & 225 & 60 & 285 & & & & \\
\hline Age & Gender & & & & & & \\
& $34-34$ & 145 & 45 & 190 & $66 \%$ & & \\
& $35-45$ & 55 & 15 & 70 & $24 \%$ & 1.74 & .250 \\
& 46 and above & 20 & 5 & 25 & $8 \%$ & & \\
& 220 & 65 & 285 & & & \\
\hline
\end{tabular}


Among 285 respondents there were 45 Professors, 60 Assistant Professors and 180 Lecturers between the age of 24 and above. The majority of respondents were between the ages of 24-34. Aforementioned table depicts the detail information about the respondents.

Aforementioned table depicts the statistics of reliability of PC (optimism, hope, resiliency and self-efficacy), CWB (workplace deviance, abusive supervision, turnover intention and working inefficiency) and EP (job commitment, job satisfaction, employee motivation and working efficiency). The values of Cronbach's $\alpha$ were $.863, .812$ and .849 for PC, CWB and EP respectively. Cronbach's $\alpha$ value above .80 is acceptable and not need to eradicate items from questionnaire (Sekaran, 2003).

Table 3: Matrix Correlation

\begin{tabular}{|c|c|c|c|c|c|}
\hline & Mean & SD & 1 & 2 & 3 \\
\hline 1. PC & 2.10 & 1.16 & .057 & & \\
\hline 2. $\mathrm{CWB}$ & 2.32 & 1.21 & .028 & $-.554 *$ & - \\
\hline 3. EP & 2.40 & 1.35 & .091 & $-.543^{*}$ & $.692^{*}$ \\
\hline
\end{tabular}

Correlation table exhibits the significant relationship among PC, CWB and EP at $(\mathrm{r}=-$ 554.*, $\mathrm{p} \leq 0.01),\left(\mathrm{r}=-543^{*}, \mathrm{p} \leq 0.01\right)$ and $\left(\mathrm{r}=.692^{*}, \mathrm{p} \leq 0.01\right)$ respectively.

Table 4: Validity and Confirmatory Factor Analysis

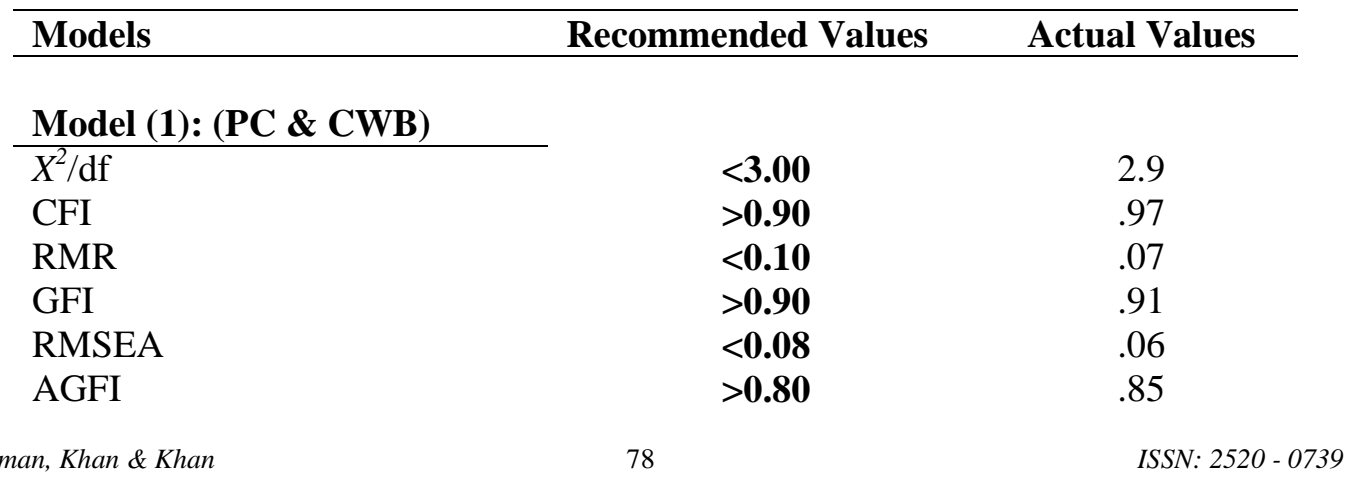


Model (2): (PC \& EP)

\begin{tabular}{l}
\hline$X^{2} / \mathrm{df}$ \\
CFI \\
RMR \\
GFI \\
RMSEA \\
AGFI \\
NNFI
\end{tabular}

$<3.00$

$>0.90$

$<0.10$

$>0.90$

$<0.06$

$>0.80$

$>0.90$

$<3.00$

$>0.90$

$<0.10$

$>0.90$

$<0.06$

$>0.80$

$>0.90$

$<3.00$

$>0.90$

$<0.10$

$>0.90$

$<0.06$

$>0.80$

$>0.90$
.93

.94

.06

.92

.07

.86

.91

2.4

.94

.08

.96

.08

.81

.97

\section{Model (4): (PC, CWB \& EP)}

CFI

RMR

GFI

RMSEA

AGFI

NNFI

\section{$n=285$ (3) factor model}

In data collection phase initially questionnaires were distributed among 32 faculty members of eight universities (4 in each university) of KP, Pakistan. The items of the questionnaire were found clear, understandable and in logical order that depicts the face validity was appropriate for data collection. Moreover, veteran faculty members of universities were asked to criticize and express their views and opinions about the questionnaire that whether the measurement instrument tool is the actual representative of the needs of the study or some other additional statements need to be added. Experts reported that all the statements were totally representative of the needs of the study which depicts the content validity is sufficient enough for data collection. For 48 questionnaire items construct validity was performed by confirmatory factor analysis (CFA) by using structure equation model (SEM). Exclusivity of three variables i.e. PC (optimism, hope, resiliency and self-efficacy), CWB (workplace deviance, abusive supervision, turnover intention and working inefficiency) and EP (job commitment, job satisfaction, employee motivation, work efficiency) were depicted in the CFA analysis.

Seven fit indices for model fitness were incorporate in the study for analysis i.e. (X²/d.f, CFI, RMR, GFI, RMSEA, AGFI and NNFI). Three factor models i.e. (PC, CWB 
and EP) demonstrate that the significant loadings on their own factors and acceptable fit. Two factor models that are (PC and CWB), (PC and EP) and (CWB and EP) respectively had considerable loadings on their own constructs among all models and all 7 fit indices were in acceptable ranges according to (Usluel, Asker \& Bas, 2008).

\section{Structural Model Analysis for Model 1 (PC \& CWB)}

Two factor model i.e. PC and controlling CWB result is as follows:

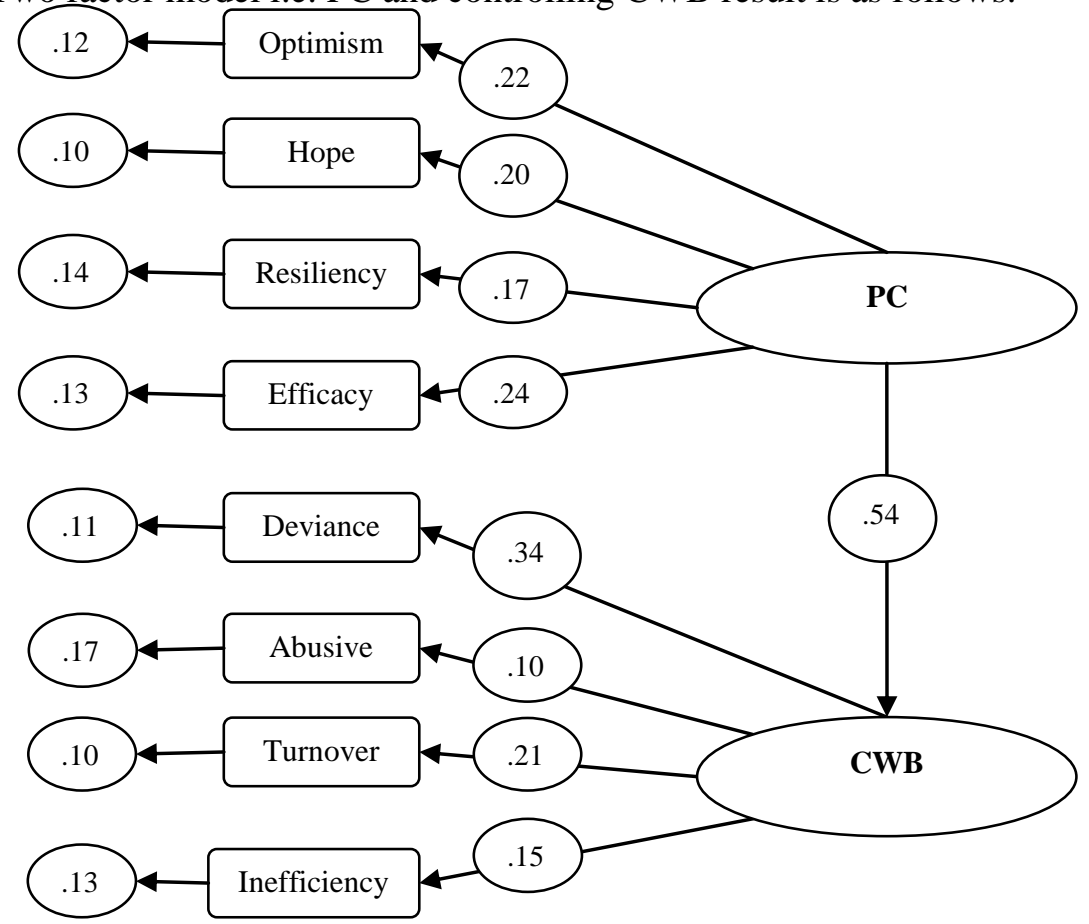

Chi-Square $=142.23, \mathrm{df}=50, \mathrm{P}$-value $=.000, \mathrm{RMSEA}=0.06$

\begin{tabular}{lcc}
\hline Fit Index & Suggested Val & Actual Val \\
\hline$X^{2} / \mathrm{df}$ & $<\mathbf{3 . 0 0}$ & 2.9 \\
\hline & & \\
CFI & $>\mathbf{0 . 9 0}$ & .97 \\
RMR & $<\mathbf{0 . 1 0}$ & .07 \\
GFI & $>\mathbf{0 . 9 0}$ & .91 \\
RMSEA & $<\mathbf{0 . 0 8}$ & .06 \\
AGFI & $>\mathbf{0 . 8 0}$ & .85 \\
NNFI & $>\mathbf{0 . 9 0}$ & .93 \\
\hline
\end{tabular}

Aforementioned table demonstrate the result of two factor model i.e. (PC and CWB). The model was evaluated through 7 fit indices that depict all the values are in normal ranges (Usluel, Asker \& Bas, 2008). Moreover, there is no need for factor loading because the variables have their own significant loadings. The direct path indicates $54 \%$ variation exist in response variable by predictors if other variables remain constant. 


\section{CFA \& Structural Model Analysis for Model 2 (PC \& EP)}

Two factor model i.e. PC and EP result is as follows:

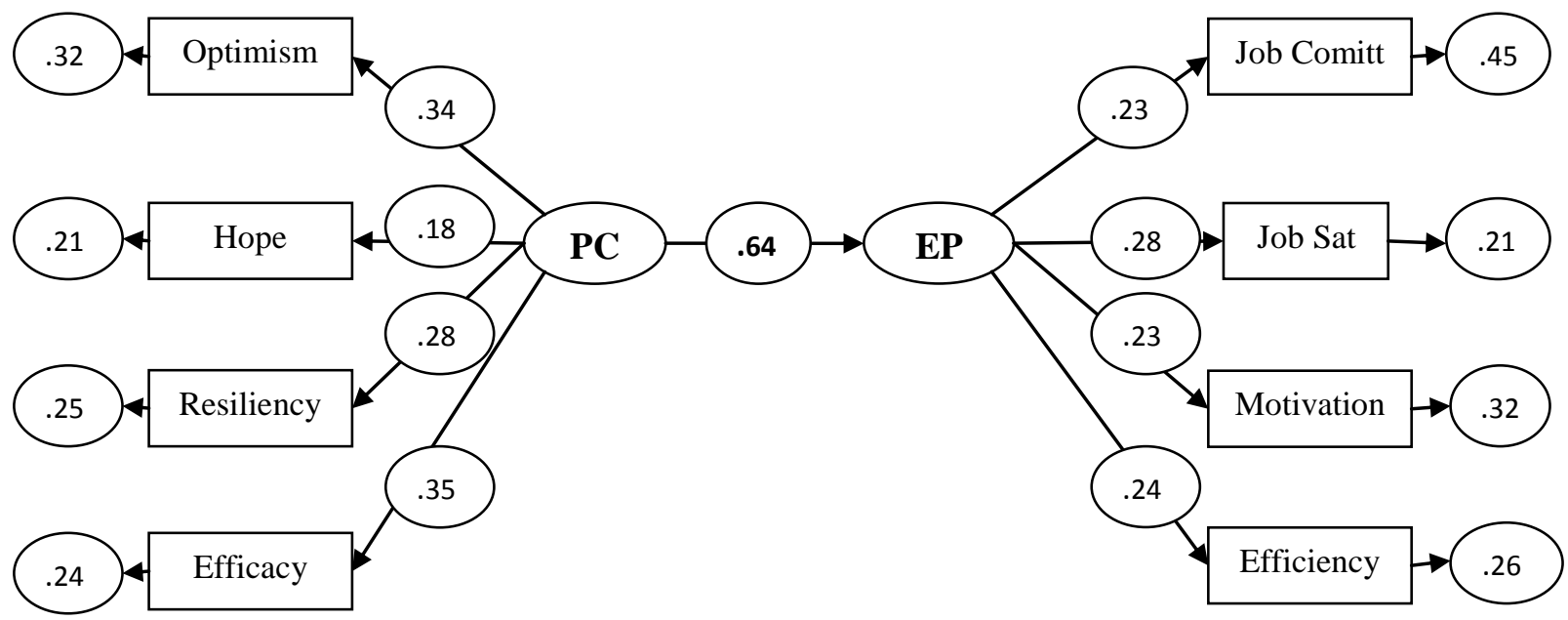

Chi-Square=104.21, df =41, P-value=.000, RMSEA=0.08

\begin{tabular}{lcc}
\hline Fit Index & Suggested Val & Actual Val \\
\hline$X^{2} / \mathrm{df}$ & $<\mathbf{3 . 0 0}$ & 2.5 \\
CFI & $>\mathbf{0 . 9 0}$ & .94 \\
RMR & $<\mathbf{0 . 1 0}$ & .06 \\
GFI & $>\mathbf{0 . 9 0}$ & .92 \\
RMSEA & $<\mathbf{0 . 0 8}$ & .07 \\
AGFI & $>\mathbf{0 . 8 0}$ & .86 \\
NNFI & $>\mathbf{0 . 9 0}$ & .91 \\
\hline
\end{tabular}

The two factor model i.e. (PC \& EP) was evaluated through 7 fit indices. All the values are in acceptable ranges according to (Usluel, Asker \& Bas, 2008) and have their own significant loadings. The direct path indicates $68 \%$ variation in response variable by the predictors. 


\section{CFA and Structural Model Analysis for Model 3 (CWB \& EP)}

Result of two factor model i.e. CWB and EP is as follows:

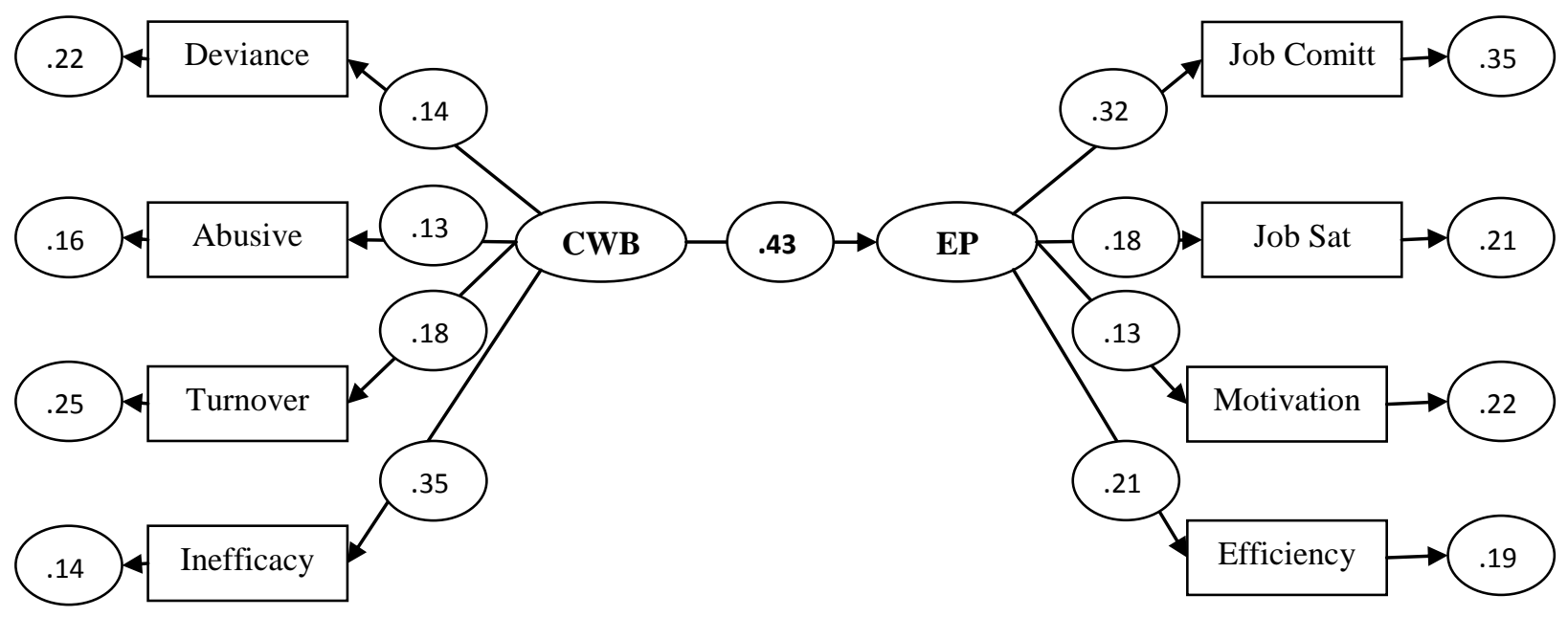

Chi-Square $=100.21, \mathrm{df}=42$, P-value $=.000$, RMSEA=0.08

\begin{tabular}{lcc}
\hline Fit Index & Suggested Val & Actual Val \\
\hline$X^{2} / \mathrm{df}$ & $<\mathbf{3 . 0 0}$ & 2.4 \\
CFI & $>\mathbf{0 . 9 0}$ & .94 \\
RMR & $<\mathbf{0 . 1 0}$ & .08 \\
GFI & $>\mathbf{0 . 9 0}$ & .96 \\
RMSEA & $<\mathbf{0 . 0 8}$ & .08 \\
AGFI & $>\mathbf{0 . 8 0}$ & .81 \\
NNFI & $>\mathbf{0 . 9 0}$ & .97 \\
\hline
\end{tabular}

The two factor model i.e. (CWB \& EP) was evaluated and found that all the computed values are in acceptable ranges (Usluel, Asker \& Bas, 2008) and have their own considerable loadings. The direct path indicates $43 \%$ variation in response variable by the predictors. 


\section{CFA and Structural Model Analysis for Model 4 (PC, CWB \& EP)}

Following is the result of three factor model i.e. (PC, CWB and EP)

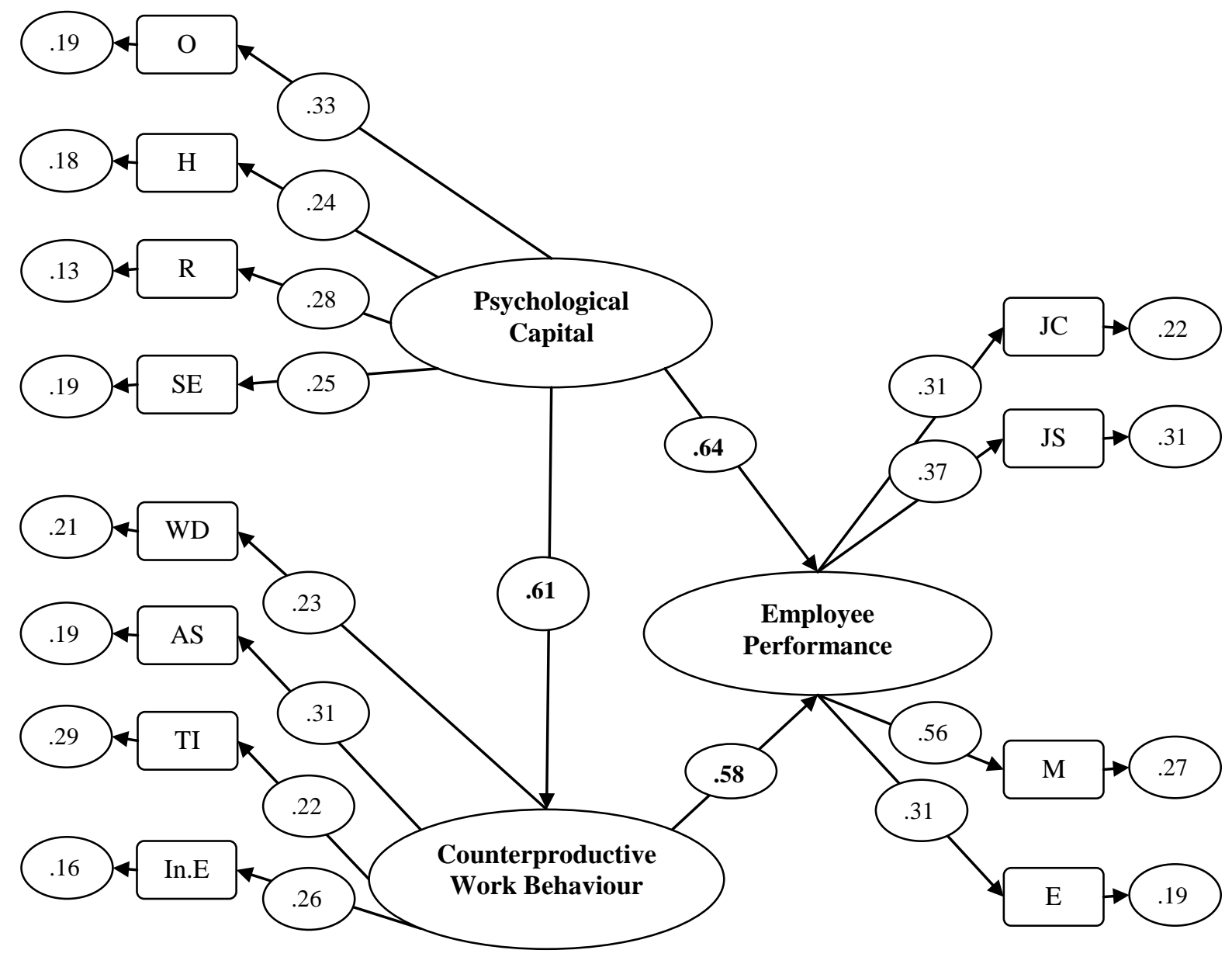

Chi-Square=116.72, df =41, P-value=.000, RMSEA=0.080

\begin{tabular}{lcc}
\hline Fit Index & Suggested Val & Actual Val \\
\hline$X^{2} / \mathrm{df}$ & $<\mathbf{3 . 0 0}$ & 2.7 \\
CFI & $>\mathbf{0 . 9 0}$ & .92 \\
RMR & $<\mathbf{0 . 1 0}$ & .02 \\
GFI & $>\mathbf{0 . 9 0}$ & .95 \\
RMSEA & $<\mathbf{0 . 0 8}$ & .08 \\
AGFI & $>\mathbf{0 . 8 0}$ & .93 \\
NNFI & $>\mathbf{0 . 9 0}$ & .98 \\
\hline
\end{tabular}

Above captioned table exhibits the 3 factor model result envisions that all the variables of the study have their own significant loadings and all the computed values are in acceptable ranges according to (Usluel, Asker \& Bas, 2008). The direct path of PC on controlling CWB, PC on EP, and controlled CWB on EP indicates $61 \%, 64 \%$ and $28 \%$ variations, if other variables remain constant. 
Table 5: Regression

\begin{tabular}{lcccccc}
\hline Variables & $\mathbf{B}$ & $\mathbf{S E}(\mathbf{B})$ & $\boldsymbol{\beta}$ & $\mathbf{T}$ & Sig. & $\mathbf{R}^{2}$ \\
\hline Step 1 & & & & & & $.618^{*}$ \\
(Constant) & 1.131 & .302 & & 5.234 & .000 & \\
PC * CWB & .617 & .040 & .823 & 19.24 & .000 & \\
PC *P & .164 & .025 & .115 & 3.59 & .000 & \\
$\begin{array}{l}\text { Step 2 } \\
\text { CWB EP }\end{array}$ & 9.74 & .530 & .956 & 25.86 & .000 & $.602^{*}$ \\
\hline $\begin{array}{l}\text { Final model: F }= \\
\text { 210.54, }\end{array}$ & $\mathbf{R = . 6 8}$ & Adj R $^{2}=\mathbf{. 6 1}$ & & & & \\
\hline
\end{tabular}

. ${ }^{*} p \leq 0.01$ Predictors $(P C, C W B)$ Response (EP)

PC and controlled CWB accounted $61 \%$ of the variance in EP. The direct path of PC towards and CWB and EP were $(\beta=0.82, \mathrm{t}=19.24, \mathrm{p}<0.05)$ and $(\beta=0.11, \mathrm{t}=3.59$, $\mathrm{p}<0.05)$ respectively. As a result both hypotheses were supported, which specified that PC have significant positive effect on controlling CWB and EP. The third hypothesis was also accepted because the direct path of controlled CWB and EP was $(\beta=0.95, t=25.86$, $\mathrm{p}<0.05)$. Multiple regression model was fit and valid.

\section{Discussion}

Reduction in CWB's within the organization is compulsory for organizational success. Drawing on the conservation of researchers (Luthans etal., 2007; Wright \& Bonett, 2007; Manzoor etal., 2013) this study explore the impact of PC including optimism, hope, resiliency and self-efficacy on CWB including workplace deviance, abusive supervision, turnover intention and worker's inefficiency) and further towards EP (job commitment, job satisfaction, motivation and efficiency). Three-factor model which contents of PC, CWB \& EP were evaluated with another models. CFA's result divulges that all statistics are in satisfactory range. Model testing demonstrates that PC has direct impacts on controlling CWB and its further impact on improving EP. PC accounted for $61 \%$ and 60\% variation in CWB and EP respectively. The result demonstrates that PC has direct impact towards reduction in CWB within the organization that further leads toward enhancing EP of education sector of KP, Pakistan. The following table depicts the study hypotheses status.

Table 6: Result Summary

\begin{tabular}{ll}
\hline Hypotheses & \multicolumn{1}{c}{ Supported/ Not Supported } \\
\hline H1: PC has significant positive impact on controlling CWB. & Supported \\
H2: PC has significant positive impact on EP. & Supported \\
H3: Controlled CWB has significant positive impact on EP. & Supported \\
\hline
\end{tabular}

\subsection{Theoretical Contributions}

Earlier Asian researchers have contributed insufficient research work in the context of PC, CWB and EP. This study explore vividly about the PC intervention towards reducing and controlling CWB's within the organization which further leads towards increase in employee job commitment, job satisfaction, motivation and worker's efficiency in Pakistani work setting. This study improves the literature in the context of PC intercession in the direction of controlling CWB's and escalating EP particularly in 
Pakistan. Study result depicts that $\mathrm{PC}$ has enduring insinuation on reducing and controlling CWB's and enhancing the EP of small and large organization.

\subsection{Recommendation}

The contemporary need of most of the organizations is to reduce or control practices like workplace deviance, abusive supervision, turnover intention and worker's inefficiency which decline the overall performance of the organization. It is recommended for the managers and directors of the organization to implement positive PC practices in order to control the CWB's within the organization and enhancing EP. Proper implementation of PC practices will improve organizational performance and economic position which further leads towards reduction in poverty and unemployment from the country. The study suggested that the CWB's should be controlled through positive PC in every organization.

\subsection{Limitations and Future Research Suggestions}

The research was partially generalized because the data was only collected from the eight universities of KP, Pakistan. In future study the contemporary hypotheses of the study should be tested in multiple samples from various universities of Pakistan with addition of some other variables pertaining to controlling CWB within the work setting of organization. The research study was cross sectional in nature so in future the research study dimension should be longitudinal with addition of more variables that should be performed in different organizations of Pakistan.

\subsection{Conclusion}

The three factors model (PC, $\mathrm{CWB}$ and $\mathrm{EP})$ reveal important and strong relationship among the variables. Whereas controlling CWB through PC was found to be essential and have strong relationship with EP. Implementation of proper PC for controlling CWB found significant values. Moreover, there exists constructive impact of PC towards controlling CWB and on improving EP. Consequently, organization makes its good will, survive in stiff competition, and increase its productivity and profitability.

\section{References}

Avey, J.B., Luthans, F. \& Youssef, C. M. (2010). The Additive Value of Psychological Capital in Predicting Workplace Attitudes and Behaviors. Journal of Management, 36 (2), 430-452.

Avolio, B. J., \& Luthans, F. (2006). The High Impact Leader: Moments Matter for Accelerating Authentic Leadership Development. New York: McGraw-Hill.

Campbell, J. P., McCloy, R. A., Oppler, S. H., \& Sager, C. E. (1993). A theory of performance. In N. Schmitt and W. C. Borman (Eds.), Personnel selection in organizations 35-70. San Francisco, CA: Jossey-Bass.

Fox, S., Spector, P. E., \& Miles, D. (2001). Counterproductive Work Behavior in Response to job Stressors and Organizational Justice: Some Mediator and moDerator tests for Autonomy and Emotions. Journal of Vocational Behavior, 59, 291-309.

Gallagher, S., Phillips, A. C., Oliver, C. \& Carroll, D. (2008). Predictors of Psychological Morbidity in Parents of Children with Intellectual Disability. Journal of Pediatric Psychology, 33, 1129-1136. 
Gruys, M. L., \& Sackett, P. R. (2003). Investigating the Dimensionality of Counterproductive Work Behavior. International Journal of Selection and Assessment, 2, 30-42. doi: 10.1111/1468 2389.00224.

Hauge, L., Skogstad, A. \& Einarsen, S. (2009). Individual and Situational Predictors of Workplace Bullying: Why do Perpetrators Engage in the Bullying of others?. Work and Stress 23 (4), 349-358.

Hogan, J., \& Hogan, R. (1989). How to Measure Employee Reliability. Journal of Applied Psychology, 74, 273-279.

Lee, A.C., Bussey T. J, Murray, E. A., Saksida, L. M., Epstein, R. A. , Kapur, N., Hodges, J. R., Graham, K. S. (2005). Perceptual deficits in amnesia: challenging the medial temporal lobe "mnemonic"' view. Neuropsychologia 43(3), 1-11.

LeBlanc, M. M., \& Kelloway, E. K. (2002). Predictors and outcomes of workplace violence and aggression. Journal of Applied Psychology, 87, 444-453.

Luthans, F., Avolio, B. J., Avey, J. B., \& Norman, S. M. (2007). Positive psychological capital: Measurement and relationship with performance and satisfaction. Personnel Psychology, 60, 541-572.

Luthans, F., \& Youssef, C. M. (2004). Human, Social, and now Positive psychological Capital Management. Organizational Dynamics, 33, 143-160.

Luthans, F., Avolio, B. J., Norman, S. M., \& Avey, J. B. (2006). Psychological Capital: Measurement and Relationship with Performance and Satisfaction. Gallup Leadership Institute Working Paper. Lincoln, NE: University of Nebraska

Luthans, F. (2002). The Need for and Meaning of Positive Organizational Behavior. Journal of Organizational Behavior, 23, 695-706.

Luthans, F., Youssef, C. M., \& Avolio, B. J. (in press). Psychological Capital. Oxford, UK: Oxford University Press.

Manzoor, S. R., \& Jalil, M. F. (2014). Psychological Capital Intervention Towards Women Entrepreneurship Development and Entrepreneurial Orientation. International Journal of Business Management \& Administration, 3(2), 22-28.

Masten, A.S., \& Reed, M.G. (2002). Resilience in Development. In C.R. Snyder \& S.J. Lopez (Eds.), The handbook of positive psychology (pp. 74-88). New York: Oxford University Press.

Norman, S.M., Avey, J.B., Nimnicht, J.L. \& Graber, N.P. (2010).The Interactive Effects of Psychological Capital and Organizational Identity on Employee Citizenship and Deviance Behaviors. Journal of Leadership and Organization Studies.

O'Leary-Kelly, A.M., Griffin, R.W., \& Glew, D. J. (1996). Organization-Motivated

Aggression: A Research Framework. Academy of Management Review, 21, 225 253.

Penney, L. M., \& Spector, P. E. (2005). Job Stress, Incivility, and Counterproductive Work Behavior (CWB): The moderating role of negative aVectivity. Journal of Organizational Behavior, 26, 777-796.

Robinson, S. L., \& Bennett, R. J. (1995). A Typology of Deviant Workplace Behaviors: A Multidimensional Scaling Study. Academy of Management Journal, 38, 555572 . 
Sackett, P., Berry, C., Wiemann, S. and Laczo, R. (2006). Citizenship and counterproductive sbehavior: Clarifying relations between the two domains. Human Performance 19 (4), 441-64.

Sekaran U (2003). Research methods for business: A skill-building approach. USA, John Willey \& Sons.

Seligman, M. E. P. (1998). Learned Optimism. New York, NY: Pocket Books.

Snyder, C. R., \& Lopez, S. (2002). Handbook of Positive Psychology. Oxford, UK: Oxford University Press.

Spector, P. E., \& Fox, S. (2002). An Emotion Centred Model of Voluntary work Behavior: Some Parallels Between Counterproductive Work Behavior and Organizational Citizenship Behavior. Human Resource Management Review, 12(2), 269-292.

Stajkovic, A., \& Luthans, F. (1998). Self-self efficacy and work-related performance: A meta-analysis. Psychological Bulletin, 44, 580-590.

Vardi, Y. \& Weitz, E. (2004). Misbehavior in Organizations Theory, Research, and Management. Lawrence Erlbaum Associates Publishers. Mahwah, New Jersey.

Usluel, Y. K., Askar, P. \& Bas, T. (2008). A Structural Equation moDel for ICT Usage in Higher Education. Education Technology Society, 11(2), 262-273.

Wright, T. A., \& Bonett, D. G. (2007). Job Satisfaction and Psychological Well-Being as non Additive predIctors of woRkplace turnover. Journal of Management, 33, $141-160$. 